\title{
The Effect of Condensation on the Morphology and Magnetic Properties of Modified Barium Hexaferrite $\left(\mathrm{BaFe}_{12} \mathrm{O}_{19}\right)$
}

\author{
Z. Durmus ${ }^{1, *}, \quad$ H. Sozeri², $\quad$ M. S. Toprak ${ }^{3}, \quad$ A. Baykal ${ }^{1}$
}

(Received 9 May 2011; accepted 6 July 2011; published online 16 July 2011.)

\begin{abstract}
We present a comparison for the effect of condensation on the morphology and magnetic properties of oleic acid modified $\mathrm{BaFe}_{12} \mathrm{O}_{19}$ nanoparticles. Two different samples of $\mathrm{BaFe}_{12} \mathrm{O}_{19}$ nanoparticles were synthesized by dehydration (Z1) and rotary evaporation (Z2) method, respectively. Oleic acid was used as the surface modification agent to observe the morphological and magnetic changes. The nanoparticles were analyzed by XRD, FTIR, TGA, SEM, and VSM techniques for structural and physicochemical characteristics. Crystallographic analysis reveals the phase as hexaferrite and the average crystallite size of Z1 and Z2 is $21 \pm 3 \mathrm{~nm}$ and $17 \pm 2 \mathrm{~nm}$, respectively. Rotary evaporator accelerates the condensation process in viscous gel (Z2). Due to the use of rotary evaporator, the coating with oleic acid for Z2 product has been accomplished very well, as compared with Z1. As a result, saturation magnetization of Z2 sample is much lower than that of Z1 sample.
\end{abstract}

Keywords: $\mathrm{BaFe}_{12} \mathrm{O}_{19}$; Nanoparticles; Rotary evaporatory; Condensation; Magnetic properties

Citation: Z. Durmus, H. Sozeri, M. S. Toprak and A. Baykal, "The Effect of Condensation on the Morphology and Magnetic Properties of Modified Barium Hexaferrite (BaFe ${ }_{12} \mathrm{O}_{19}$ )", Nano-Micro Lett. 3 (2), 108-114

(2011). http://dx.doi.org/10.3786/nml.v3i2.p108-114

\section{Introduction}

With the fast advancement of wireless communication during the past few decades, microwave absorbing materials are becoming increasingly important for the applications outside special fields such as silent rooms, radar systems and military applications. Among these microwave absorbers, barium hexaferrite as a hard magnetic material, may be the most extensively investigated material among the family of hard ferrites having the general formula $\mathrm{MeFe}_{12} \mathrm{O}_{19}$, where $\mathrm{Me}=\mathrm{Ba}$, $\mathrm{Sr}$, or $\mathrm{Pb}$, due to of its two outstanding properties of having high saturation magnetization and high magnetic anisotropy field (1.7 $\mathrm{T}$ for $\mathrm{BaFe}_{12} \mathrm{O}_{19}$ ), which results in a high coercivity, remanence and a ferromagnetic resonance at around $50 \mathrm{GHz}[1]$ and excellent chemical stability $[2,3]$. The ferromagnetic resonance coincides with large magnetic losses, making these materials suitable for microwave absorbers. Therefore, it has already found applications as permanent magnets, high density recording media, as well as microwave devices. Fine particles of $\mathrm{BaFe}_{12} \mathrm{O}_{19}$ are used in high density perpendicular magnetic recording media with dimensions in nanometers and have attracted much attention because of their different magnetic and electrical properties, comparing with those of their bulk counterpart and potential applications in various fields [4].

The size of the particles for better magnetic properties can be controlled during preparation, depending on the production technique, or post preparation, by mechanical $[5,6]$ or thermal treatments [7-9]. Aerosol

\footnotetext{
${ }^{1}$ Department of Chemistry, Fatih University, B. Cekmece, 34500 B.Cekmece-?stanbul, Turkey

${ }^{2}$ TUBITAK-UME, National Metrology Institute, PO Box 54, 41470 Gebze-Kocaeli, Turkey

${ }^{3}$ Functional Materials Division, Royal Institute of Technology-KTH, SE16440 Stockholm, Sweden

*Corresponding author. E-mail: zhrdurmus@gmail.com; Tel: +902128663300/2070; Fax: +902128663402
} 
pyrolysis [10], chemical co-precipitation [11], hydrothermal reaction [12], sol-gel [13], oxidation technique using nitric acid $\left(\mathrm{HNO}_{3}\right)$ [14] and self-propagating high temperature synthesis $[15,16]$ are some examples. Among these methods, the facile lower temperature chemical methods have potential advantages of relatively low cost, as well as avoiding the use of complicated processes and special instruments. Gao et al., synthesized $\mathrm{CuO}$ nanoribbon arrays by a simple dehydration reaction and the products exhibit excellent hydrogen storage capacity and big BET surface area [17]. Kumta et al. synthesized the $\mathrm{LiCoO}_{2}$ powders for lithium-ion batteries by rotary evaporation [18].

In order to synthesize fine particles with good magnetic properties, there are some essential factors, which should be carefully taken into account depending on the preparation method followed. Calcination temperature and time, for example, is of primary importance during the synthesis, which determines the average particle size. The higher calcination temperature results in the larger particle size. The Ba:Fe ratio is another factor, which affects the phase purity of the samples. It may vary depending on the synthesis route followed. For instance, single phase samples were obtained when it is around 1:11 in the sol-gel technique [19], when ball milling was used optimum ratio is 1:12 [20], 1:10 in the coprecipitation route [11], and it is 1:4 in the hydrothermal method [21]. Pre-heating between $400^{\circ} \mathrm{C}$ and $500^{\circ} \mathrm{C}$ for several hours was reported as a key factor to prevent formation of $\alpha-\mathrm{Fe}_{2} \mathrm{O}_{3}$ phase in the sol-gel technique [22]. In this way, samples with coercive field of $5950 \mathrm{Oe}$ and having magnetization of $70 \mathrm{emu} / \mathrm{g}$ have been synthesized [23].

Oleic acid is often used as a surfactant to form a waterproof shell around the magnetic particles, since oleic acid has a higher affinity to the surface of ultra fine magnetic particles as compared to other surfactants $[24,25]$.

In this study, we present the effect of condensation on the morphology and magnetic properties of oleic acid modified $\mathrm{BaFe}_{12} \mathrm{O}_{19}$ nanoparticles.

\section{Experimental}

\section{Instrumentation}

X-ray powder diffraction (XRD) analysis was conducted on a Rigaku Smart Lab operated at $40 \mathrm{kV}$ and $35 \mathrm{~mA}$ using $\mathrm{Cu} \mathrm{K}$ radiation $(\lambda=1.54059 \AA)$.

Fourier transform infrared (FT-IR) spectra of the samples were recorded with a Perkin Elmer BX FT-IR infrared spectrometer in the range of $400 \sim 4000 \mathrm{~cm}^{-1}$.

Scanning Electron Microscopy (SEM) analysis was performed, in order to investigate the microstructure of the sample, using JEOL 6335F, Field Emission Gun. Samples were coated with gold at $10 \mathrm{~mA}$ for $2 \mathrm{~min}$ prior to SEM analysis.

The thermal stability was determined by thermogravimetric analysis (TGA, Perkin Elmer Instruments model, STA 6000). The TGA thermograms were recorded for $5 \mathrm{mg}$ of powder sample at a heating rate of $10^{\circ} \mathrm{C} / \mathrm{min}$ in the temperature range of $30 \sim 750^{\circ} \mathrm{C}$ under nitrogen atmosphere.

VSM measurements were performed by using a Vibrating sample magnetometer (LDJ Electronics Inc., Model 9600). The magnetization measurements were carried out in an external field up to $15 \mathrm{kOe}$ at room temperature.

\section{Procedure}

The starting materials, iron (III) nitrate nonahydrate $\left(\mathrm{Fe}\left(\mathrm{NO}_{3}\right)_{3} \cdot 9 \mathrm{H}_{2} \mathrm{O}\right)$, barium nitrate $\left(\mathrm{Ba}\left(\mathrm{NO}_{3}\right)_{2}\right)$, sodium hydroxide $(\mathrm{NaOH})$, citric acid $\left(\mathrm{C}_{6} \mathrm{H}_{8} \mathrm{O}_{7} \cdot \mathrm{H}_{2} \mathrm{O}\right)$, and oleic acid $\left(\mathrm{C}_{18} \mathrm{H}_{34} \mathrm{O}_{2}\right)$ were purchased from Alfa Aesar, having analytical purity. $\mathrm{Ba}\left(\mathrm{NO}_{3}\right)_{2}$ and $\mathrm{Fe}\left(\mathrm{NO}_{3}\right)_{3} \cdot 9 \mathrm{H}_{2} \mathrm{O}$ weighed in the stoichiometry of $\mathrm{BaFe}_{12} \mathrm{O}_{19}$ to prepare the aqueous solution of each with the respective concentrations of 0.1 and $0.6 \mathrm{M}$ by stirring at $50^{\circ} \mathrm{C}$ with $\mathrm{Fe} / \mathrm{Ba}$ ratio of $11: 1$ and were gradually added into the citric acid solution under continuous magnetic stirring. The molar ratio of metal nitrates to citric acid was adjusted at 1:1. The $\mathrm{pH}$ of the solution was continually monitored and maintained at a value of 7 by the addition of the sodium hydroxide solution required. The temperature was raised to $65^{\circ} \mathrm{C}$ and the solution was then stirred for $2 \mathrm{~h}$ at $65^{\circ} \mathrm{C}$. Then $30 \mathrm{ml}$ oleic acid was slowly added to the solution and mixed again for $2 \mathrm{~h}$. Afterwards, the final solution was divided into two parts. First part (Z1) solution was allowed to dehydrate in a vacuum oven at $180^{\circ} \mathrm{C}$ for $48 \mathrm{~h}$. Second part (Z2) solution was magnetically stirred for $12 \mathrm{~h}$ at room temperature, and then it was transferred to a rotary evaporator and evaporated at $90^{\circ} \mathrm{C}$ for $3 \mathrm{~h}$ to remove surplus water until a viscous liquid was obtained. Thus, it was observed that rotary evaporator accelerated the condensation process in viscous gel (Z2). Due to the use of rotary evaporator, the coating with oleic acid for Z2 product was accomplished very well as compared with Z1. By increasing the temperature, the gel precursors were combusted forming brown loose powder precursors (denoted Z2p, Z1p). These powders were precalcined at $450^{\circ} \mathrm{C}$ for $4 \mathrm{~h}$, followed by calcination at $1100^{\circ} \mathrm{C}$ for $1 \mathrm{~h}$. The modified hexaferrite $\mathrm{BaFe}_{12} \mathrm{O}_{19}$ nanoparticles were thus obtained.

\section{Results and Discussion}

\section{SEM Analysis}

The morphology of as prepared samples was analyzed by SEM and the micrographs are presented in Fig. 1(a) 
and Fig. 1(b) for Z1 and Z2, respectively. Both samples exhibit nanoparticles with several different morphologies including polygonic, rod-like, and plate like morphologies [26]. Z1 exhibits particles with size in the range of $40 \mathrm{~nm}$ to $500 \mathrm{~nm}$. Sample Z2, however, shows slightly narrow size distribution in the range of ca. $40 \mathrm{~nm}$ to $260 \mathrm{~nm}$. When compared with the crystallite sizes obtained from the XRD line profile fitting, (Z1: $21 \pm 3 \mathrm{~nm}$ and Z2: $17 \pm 2 \mathrm{~nm}$ ) it is obvious that the particles observed by SEM are secondary particles with polycrystalline character for both samples.
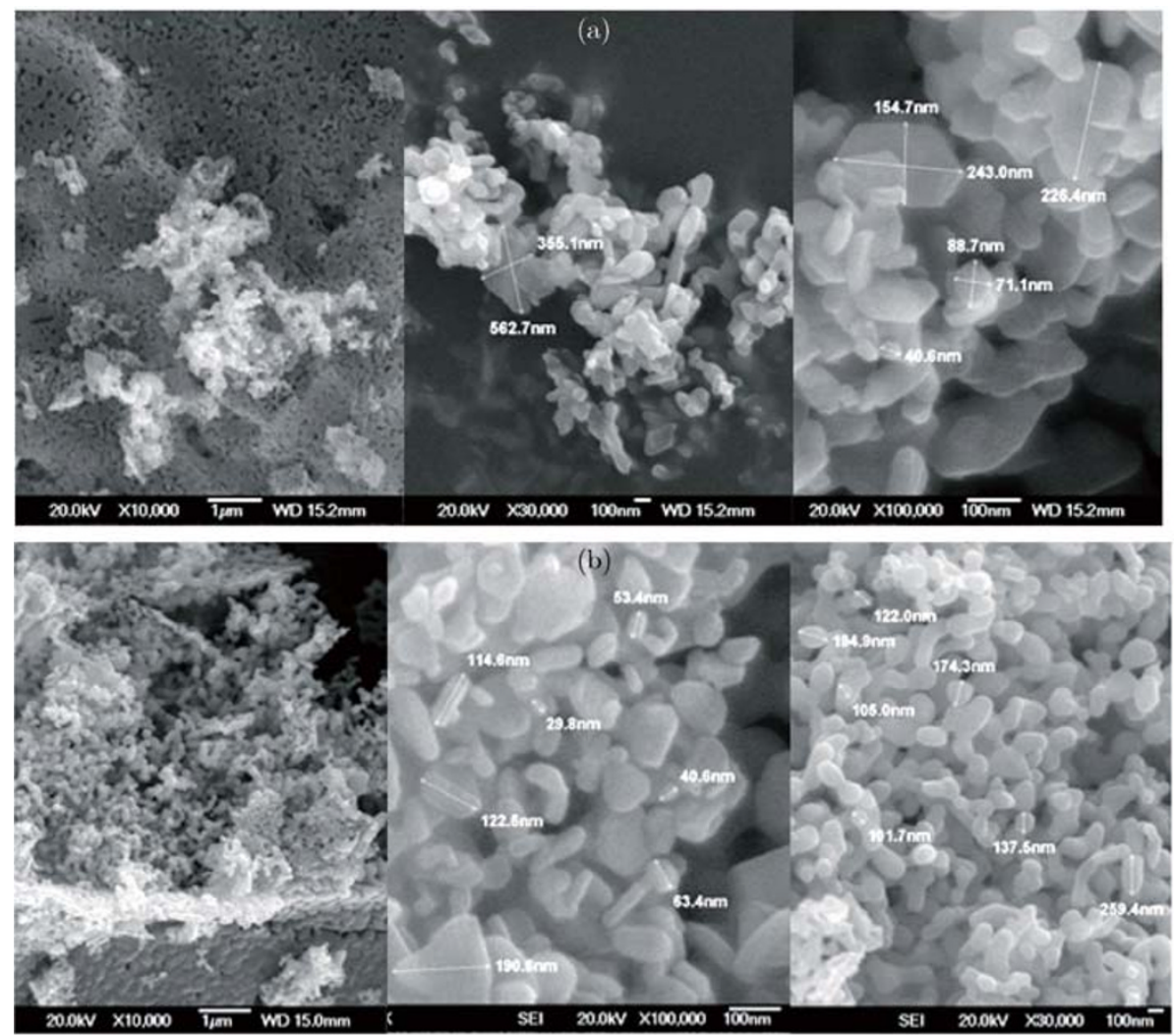

Fig. 1 SEM imagnes of: (a) Z1 at different magnifications; and (b) Z2 at different magnifications.

\section{FT-IR Analysis}

Figure 2 shows the FTIR spectra for the gel precursors (Z2p, Z1p), oleic acid and samples calcined (Z1, $\mathrm{Z} 2)$ at $1100^{\circ} \mathrm{C}$. The spectrum of oleic acid exhibit sharp bands at $2924 \mathrm{~cm}^{-1}$ and $2854 \mathrm{~cm}^{-1}$ and $1405 \mathrm{~cm}^{-1}$ the symmetric $\left(v_{\mathrm{s}} \mathrm{C}-\mathrm{H}\right)$ and asymmetric $\left(v_{\mathrm{as}} \mathrm{C}-\mathrm{H}\right) \mathrm{CH}_{2}$ stretching modes and stretching mode of $\mathrm{COOH}$ group of the oleyl group, respectively. These characteristic peaks of oleic acid disappear after the ligand-metal interaction. The intense peak at $1710 \mathrm{~cm}^{-1}$ (oleic acid molecule) is derived from the existence of the $\mathrm{C}=\mathrm{O}$ stretch, and the band at $1285 \mathrm{~cm}^{-1}$ exhibits the presence of the $\mathrm{C}-\mathrm{O}$ stretch. The $\mathrm{O}-\mathrm{H}$ in-plane and outof-plane bands appear at $1462 \mathrm{~cm}^{-1}$ and $937 \mathrm{~cm}^{-1}$, respectively [27-31]. A set of bands appear at 1381 and $848 \mathrm{~cm}^{-1}$, which are attributed to the $\mathrm{N}-\mathrm{O}$ stretching and bending vibrations of $\mathrm{NO}_{3}^{-}$, respectively [32-34].

When the oleic acid molecule is adsorbed as a surfactant, the adsorption will result in some change in the spectra of the surfactant. For example, the adsorption

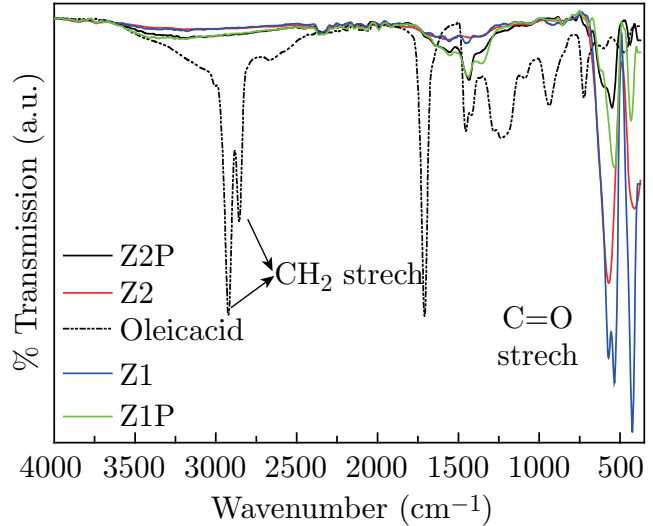

Fig. 2 FT-IR spectra of the dried precursors (Z1p, and $\mathrm{Z} 2 \mathrm{p}$ ), oleic acid and precursors calcined at $1100^{\circ} \mathrm{C}$ for $1 \mathrm{~h}$ (Z1 and Z2).

band at $1710 \mathrm{~cm}^{-1}$ (oleic acid molecule), which is assigned to stretching vibrations of $\mathrm{C}=\mathrm{O}$ of the carboxyl group, disappears in the spectrum of the final magnetic fluid $[27,35]$. All these results suggest the existence of both oleic acid molecule and oleate in the magnetic par- 
ticles, thus leading to the conclusion that physical adsorption and chemical binding were formed on the surface of magnetic particles, resulting in significant improvement in hydrophobicity after modification.

From Fig. 2, it can be seen that before modification (calcined at $1100^{\circ} \mathrm{C}$ ), the adsorption bands at $448 \mathrm{~cm}^{-1}, 552 \mathrm{~cm}^{-1}$ and $603 \mathrm{~cm}^{-1}$ correspond to typical $\mathrm{BaFe}_{12} \mathrm{O}_{19}$ adsorption bands [36-40].

\section{XRD Analysis}

Phase investigation of the crystallized products (Z1, Z2) was performed by XRD and the diffraction pattern is presented in Fig. 3. The XRD powder patterns indicate that the products are M-type $\mathrm{BaFe}_{12} \mathrm{O}_{19}$ and the diffraction peaks are broadened owing to very small crystallite size. All of the observed diffraction peaks are indexed by the hexagonal structure of $\mathrm{BaFe}_{12} \mathrm{O}_{19}$ revealing a high phase purity of hexaferrite agree with those reported in JCPDS, card number 84-0757 (including minor $\mathrm{Fe}_{2} \mathrm{O}_{3}$ (for Z1) card number 76-1821).
The mean size of the crystallites was estimated from the diffraction pattern by line profile fitting method using the equation (1) given in [41,42]. The line profile, shown in Fig. 3(a) was fitted for 27 observed peaks for Z1 with the following miller indices: (100), (002), (102), (006), (106), (110), (107), (114), (108), (202), (203), (116), (1010), (118), (1011), (213), (216), (2010), (300), (217), (2011), (218), (307), (2010), (200), (1114), (2014) and including minor phase $\mathrm{Fe}_{2} \mathrm{O}_{3}$ was given with $\left(^{*}\right)$ on Fig. 3(a). Figure 3(b) was fitted for 22 observed peaks for Z2 with the following miller indices: (100), (002), (102), (006), (106), (110), (008), (112), (107), (114), (200), (203), (116), (205), (118), (1011), (209), (300), (217), (2011), (200), and (2014). The average crystallite, size, D and $\sigma$, was obtained as for $\mathrm{Z} 1=21 \pm 3$ $\mathrm{nm}$ and $\mathrm{Z} 2=17 \pm 2 \mathrm{~nm}$, as a result of this line profile fitting. In Fig. 3(c), bulk (unmodified) $\mathrm{BaFe}_{12} \mathrm{O}_{19}$ is shown to compare the effect of surface modification on the size and particle size of oleic acid modified nanoparticles, which was observed to be smaller compared to the unmodified sample.

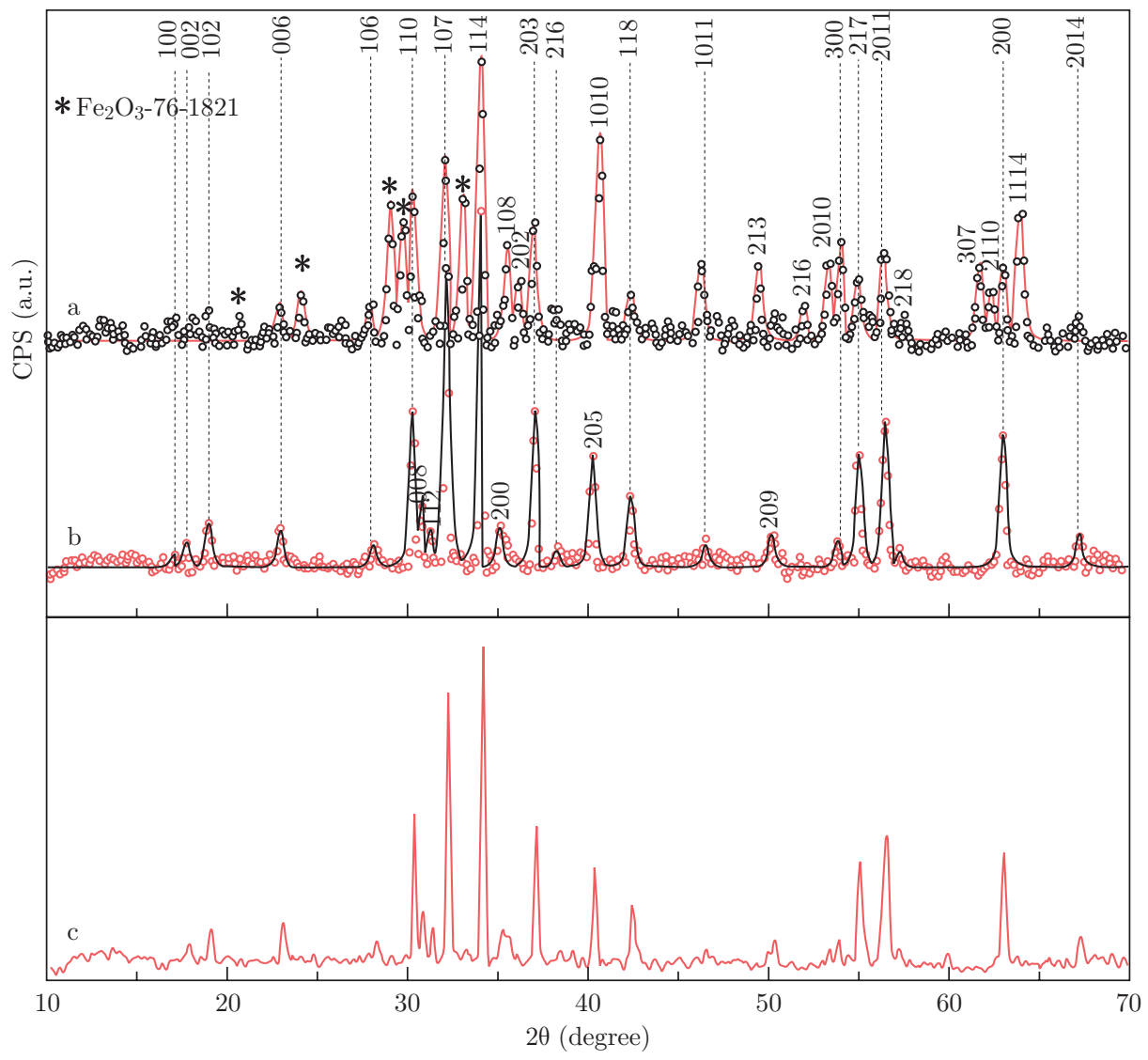

Fig. 3 XRD powder patterns and line profile fittings of: (a) Z1; and (b) Z2; and (c) bulk $\mathrm{BaFe}_{12} \mathrm{O}_{19}$.

\section{TG Analysis}

Thermogravimetric analysis is carried out to evaluate the mechanism for the formation of hexaferrite phase and to observe the effect of heating on structural changes of the synthesized sample. Figure shows three thermographs indicating the weight losses at $100^{\circ} \mathrm{C}$, $300^{\circ} \mathrm{C}$ and $650^{\circ} \mathrm{C}$. The first peak at $100^{\circ} \mathrm{C}$ is due to the loss of residual water in the gel [26]. The second weight loss around $300^{\circ} \mathrm{C}$ is due to condensation and the de- 
composition of the unreacted citric acid that remained after combustion [43]. The third peak extending up to $600^{\circ} \mathrm{C}$ is due to further condensation (the decarboxylation of $\mathrm{BaCO}_{3}$ formed during the combustion, which has been reported to take place at $1055^{\circ} \mathrm{C}$ for pure carbonate and at around $800^{\circ} \mathrm{C}$ for a mixture carbonate and an iron oxide $[26,43,44]$. This peak could also be assigned to simultaneous formation of monoferrite, $\left.\mathrm{MFe}_{2} \mathrm{O}_{4}(\mathrm{M}=\mathrm{Ba}, \mathrm{Sr})[26]\right)$.

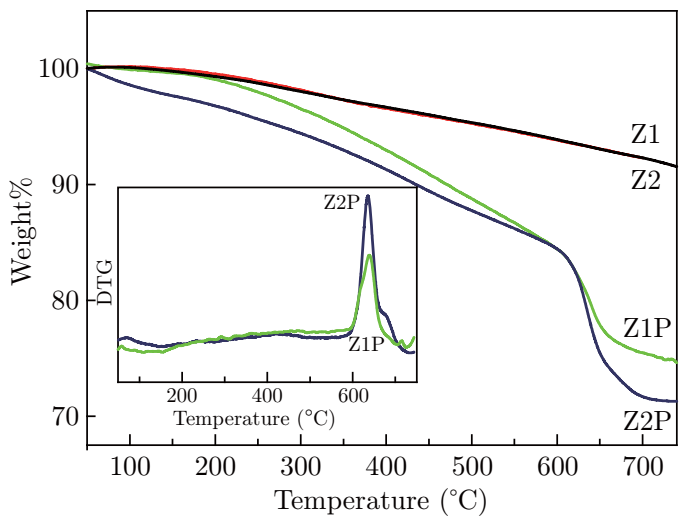

Fig. 4 TGA thermograms of precursor (Z2p, Z1p) and calcined $(\mathrm{Z} 2, \mathrm{Z} 1)$ hexaferrite powders.

\section{VSM Analysis}

Room temperature $\mathrm{M}-\mathrm{H}$ hysterisis curves of bulk (i.e., as annealed) $\mathrm{BaFe}_{12} \mathrm{O}_{19}$ particles and oleic acid modified $\mathrm{BaFe}_{12} \mathrm{O}_{19}(\mathrm{Z1}, \mathrm{Z} 2)$ are shown in Fig. 5. It is observed that bulk $\mathrm{BaFe}_{12} \mathrm{O}_{19}$ and $\mathrm{Z} 1$ has nearly the same saturation magnetization (Ms) and measured 61 $\mathrm{emu} / \mathrm{g}$ while that of Z2 is $38 \mathrm{emu} / \mathrm{g}$. Similarly, coercive fields of bulk and $\mathrm{Z} 2$ samples are $5 \mathrm{kOe}$ and that of $\mathrm{Z} 1$ is $4.5 \mathrm{kOe}$. The reason of the weak magnetization of sample $\mathrm{Z} 1$ can be explained by the formation of the intermediate hematite phase $\left(\alpha-\mathrm{Fe}_{2} \mathrm{O}_{3}\right)$, see Fig. 3(c). The presence of this phase is relatively higher in $\mathrm{Z} 1$ compared to $\mathrm{Z} 2$, thus, it is quite reasonable to have low saturation magnetization. Existance of this intermediate phase is often observed when barium hexaferrite is synthesized with initial Fe/Ba molar ratio of 12:1. To avoid the formation this impurity, optimal $\mathrm{Fe} / \mathrm{Ba}$ molar ratio should be choosen. It was reported that the optimum $\mathrm{Fe} / \mathrm{Ba}$ ratio is 4:1 for hydrothermal route [45], 10 for co-precipitation [9] and 11 in the microwave induced combustion method [46]. Generally, formation of $\alpha-\mathrm{Fe}_{2} \mathrm{O}_{3}$ can be prevented by choosing the $\mathrm{Fe} / \mathrm{Ba}$ ratio in between 11.5:1 and 10:1, further decrease leads to the formation of another intermediate phase, barium monoferrite $\left(\mathrm{BaFe}_{2} \mathrm{O}_{4}\right)$. Fortunately, this phase can be removed by $\mathrm{HCl}$ etching [47]. In this way, Sozeri et al. very recently succeed to synthesize high purity and high quality barium hexaferrite samples with an initial $\mathrm{Fe} / \mathrm{Ba}$ molar ratio of 2:1 [48]. XRD pattern of sample $\mathrm{Z} 1$ also has a low intensity peak of hematite, fraction of which is very low and magnetization of this sample appeared to be very close to that of bulk sample [49].

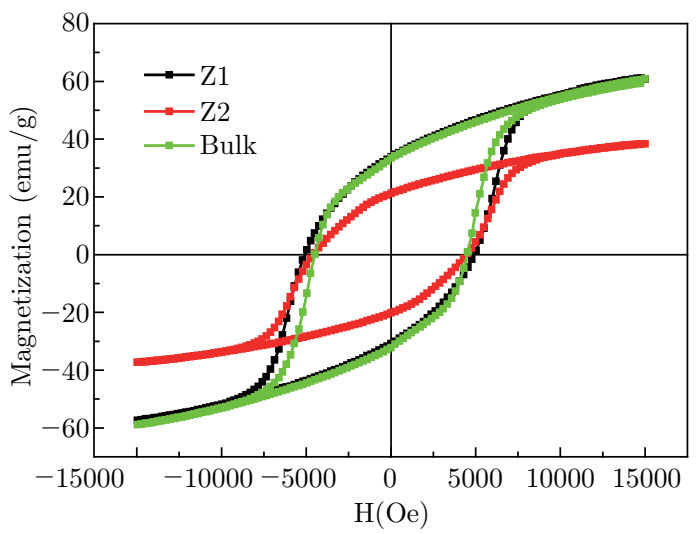

Fig. 5 Magnetic field vs. magnetization plots Z1, Z2 and bulk $\mathrm{BaFe}_{12} \mathrm{O}_{19}$ (unmodified).

The reason of the low coercive field of the sample Z1 is due to its large particle size. SEM micrographs and crystallite size calculations from XRD patterns showed that $\mathrm{Z} 1$ has larger grains as $\approx 21 \pm 6 \mathrm{~nm}$ in average size. It is known that as the grain size increases, coercivity of the sample decreases. In fact, the coercivity is related to the reciprocal grain size rather than the grain size itself [47]. Pinning of the magnetization occurs at the grain boundaries, density of which decreases as grain size increases. Therefore, when the grain size greatly increases, the coercivity caused by grain boundary pinning would disappear, because each grain can be in multi-domain state.

\section{Conclusion}

The preparation of fine particles of $\mathrm{BaFe}_{12} \mathrm{O}_{19}$ was accomplished by gel to crystalline conversion method in the present study. Oleic acid has been used as a surface modification agent in order to observe the morphological and magnetic changes. Comparing the crystallite sizes obtained from the XRD line profile fitting, (Z1: $17 \pm 2 \mathrm{~nm}$ and Z2: $21 \pm 3 \mathrm{~nm}$ ) it is obvious that the particles observed in SEM are secondary particles with polycrystalline character for both samples. Although the ratio of $\mathrm{Fe} / \mathrm{Ba}$ was taken as 11:1, this study shows that $\mathrm{BaFe}_{12} \mathrm{O}_{19}$ nanoparticles synthesized by the rotary method is almost pure but $\mathrm{BaFe}_{12} \mathrm{O}_{19}$ nanoparticles synthesized by dehydration contains $\alpha-\mathrm{Fe}_{2} \mathrm{O}_{3}$ as impurity. Due to the accelerated condensation process observed for Z2, the resulting thickness of oleic acid coating is high. Thus, saturation magnetization of Z2 sample is much lower (nearly half) compared to that of Z1. 


\section{Acknowledgements}

The authors are thankful to the Fatih University, Research Project Foundation (Contract No: P50020902-2) and Turkish Ministry of Industry and TUBITAK (Contract No: 110T487) for financial support of this study.

\section{References}

[1] J. Smit and H. P. J. Wijn, "Ferrites", Eindhoven, Philips' technical library, 1959.

[2] Y. W. Dou, "Ferrite", Jiangsu Science and Technology Press, Nanjing, China, 1996.

[3] N. Dishovske, A. Petkov, I. Nedkov and I. Razkazov, IEEE Trans. Magn. 30, 969 (1994). http://dx.doi. org/10.1109/20.312461

[4] M. J. Iqbal, M. N. Ashiq, P. H. Gomez and J. M. Munoz, J. Magn. Magn. Mater. 320, 881 (2008). http://dx.doi.org/10.1016/j.jmmm.2007.09.005

[5] S. J. Campbell, W. A. Kaczmarek, E. Wu and K. D. Jayasuriya, IEEE Trans. Magn. 30, 742 (1994). http://dx.doi.org/10.1109/20.312394

[6] S. J. Campbell, E. Wu, W. A. Kaczmarek and K. D. Jayasuriya, Hyperfine Inter. 92, 933 (1994). http:// dx.doi.org/10.1007/BF02065715

[7] V. K. Sankaranarayanan, Q. A. Pankhurst, D. P. E. Dickson and C. E. Johnson, J. Magn. Magn. Mater. 125, 199 (1993). http://dx.doi.org/10.1016/ 0304-8853 (93) 90838-S

[8] S. J. Campbell, W. A. Kaczmarek and G. M. Wang, Nanostruct. Mater. 6, 687 (1995). http://dx.doi. org/10.1016/0965-9773(95) 00151-4

[9] P. G. Bercoff and H. R. Bertorello, J. Magn. Magn. Mater. 205, 261 (1999). http://dx.doi.org/10.1016/ S0304-8853 (99) 00471-0

[10] Z. X. Tang, S. Nafis, C. M. Sorensen and G. C. Hadjipanayis, IEEE Trans. Magn. 25, 4236 (1989). http:// dx.doi.org/10.1109/20.42580

[11] S. R. Janasi, M. Emura, F. J. Landgraf and D. J. Rodrigues, IEEE Trans. Magn. 36 (2000) 3327. http:// dx.doi.org/10.1109/20.908788

[12] D. Barb, L. Diamandescu, A. Rusi, D. TarabasanuMihaila, M. Morariu and V. Teodorescu, J. Mater. Sci. 21, 1118 (1986). http://dx.doi.org/10.1007/ BF00553240

[13] W. Zhong, W. Ding, N. Zhang, J. Hong, Q. Yan and Y. Du, J. Magn. Magn. Mater. 168, 196 (1997). http:// dx.doi .org/10.1016/S0304-8853(96)00664-6

[14] H. Sozeri, J. Magn. Magn. Mater. 321, 2717 (2009). http://dx.doi.org/10.1016/j.jmmm.2009.03.075

[15] L. Affleck, M. D. Aguas, I. P. Parkin, Q. A. Pankhurst and M. V.Kuznetsov, J. Mater. Chem. 10, 1925 (2000). http://dx.doi.org/10.1039/b002431g

[16] H. Sozeri and N. Ghazanfari, Mat. Chem. Phys. 113, 977 (2009). http://dx.doi.org/10.1016/j. matchemphys. 2008.08.079

[17] P. Gao, Y. Chen, H. Lv, X. Li, Y. Wang and Q. Zhang, Int J. Hydro. Energy 34, 3065 (2009). http://dx. doi. org/10.1016/j.ijhydene. 2008.12.050
[18] P. N. Kumta, D. Gallet, A. Waghray, G. E. Blomgren and M. P. Setter, J. Power Sources 72, 91 (1998). http://dx.doi.org/10.1016/ S0378-7753 (97) 02680-3

[19] G. Mendoza-Suarez, M. C. Cisneros-Morales, M. M. Cisneros-Guerrero, K. K. Johal, H. Mancha-Molinar, O. E. Ayala-Valenzuela and J. I. Escalante-Garcia, Mater. Chem. Phys. 77, 796 (2002). http://dx.doi. org/10.1016/S0254-0584(02)00141-4

[20] G. Mendoza-Suarez, J. A. Matutes-Aquino, J. I. Escalante-Garcia, H. Mancha-Molinar, D. RiosJara and K. K. Johal, J. Magn. Magn. Mater. 223, 55 (2001). http://dx.doi.org/10.1016/ S0304-8853(00) 00583-7

[21] S. Che, J. Wang and Q. Chen, J. Phys. Condens. Matter 15, L335 (2003). http://dx.doi.org/10.1088/ 0953-8984/15/22/101

[22] W. Zhong, W. Ding, N. Zhang, J. Hong, Q. Yan, and Y. Du, J. Magn. Magn. Mater. 168, 196 (1997). http://dx.doi.org/10.1016/ S0304-8853 (96) 00664-6

[23] C. Surig, K. A. Hempel and Ch. Sauer, J. Magn. Magn. Mater. 157. 268 (1996). http://dx.doi.org/10.1016/ 0304-8853(95) 01201-X

[24] V. V Korolev, A. G. Ramazanova and A. V. Blinov, Russ. Chem. Bull. 51, 2044 (2002). http://dx.doi. org/10.1023/A: 1021655708965

[25] S. Kong, P. Zhang, X. Wen, P. Pi, J. Cheng, Z. Yang and J. Hai, Particuology 6, 185 (2008). http://dx. doi.org/10.1016/j.partic. 2008.03.004

[26] A. Mali and A. Ataei, Scripta Mat. 53, 1065 (2005). http://dx.doi.org/10.1016/j.scriptamat. 2005.06 .037

[27] H. Sozeri, J. Alloys Comp. 486, 809 (2009).

[28] G. Li, W. Peng, X. Li, X. Fan, X. Li, G. Zhang and F. Zhang, App. Surf. Sci. 254, 4970 (2008). http://dx. doi.org/10.1016/j.apsusc . 2008.01.167

[29] Q. Lan, C. Liu, F. Yang, S. Liu, J. Xu and D. Sun, J. Coll. Inter. Sci. 310, 260 (2007). http://dx.doi.org/ $10.1016 / j$.jcis. 2007.01 .081

[30] L. Zhang, R. He and H. C. Gu, Appl. Surf. Sci. 253, 2611 (2006). http://dx.doi.org/10.1016/j.apsusc . 2006.05 .023

[31] S. Maenosonoa, T. Suzuki, and S. Saita J. Magn. Magn. Mater. 320, L79 (2008). http://dx.doi.org/ 10.1016/j.jmmm.2008.01.026

[32] R. C. Pullar and A. K. Bhattacharya, J. Magn. Magn. Mater. 300, 490 (2006). http://dx.doi.org/10.1016/ j.jmmm. 2005.06.001

[33] A. Baykal, N. Kasapoglu, Y. Köseoglu, A. C. Basaran, H. Kavas and M. S. Toprak, Cent. Eur. J. Chem. 6, 125 (2008). http://dx.doi.org/10.2478/ s11532-007-0070-4

[34] N. Kasapoglu, A. Baykal, Y. Koseoglu and M. S. Toprak, Scripta Mater. 57, 441 (2007). http://dx. doi.org/10.1016/j.scriptamat.2007.04.042

[35] V. V. Korolev, A. G. Ramazanova and A. V. Blinov, Particuology 6, 185 (2008). http://dx.doi.org/10. $1016 / j$.partic. 2008.03.004 
[36] B. Birsöz, A. Baykal, H. Sözeri and M. S. Toprak, J. Alloys Comp. 493, 481 (2010). http://dx.doi.org/ 10.1016/j.jallcom.2009.12.135

[37] Z. Durmus, B. Unal, M. S. Toprak, H. Sozeri and A. Baykal, Polyhedron 30, 1349 (2011). http://dx.doi. org/10.1016/j.poly.2011.02.044

[38] Z. Durmus, B. Unal, M. S. Toprak, A. Baykal and A. Aslan, Physica B 406, 2298 (2011). http://dx.doi. org/10.1016/j.physb. 2011.03.063

[39] B. Unal, Z. Durmus, A. Baykal, M. S. Toprak, H. Sozeri and A. Bozkurt, J. Alloys Comp. In press. http:// dx.doi.org/10.1016/j.jallcom.2011.05.001

[40] X. Tang, B. Y. Zhao, K. A. Hu, J. Mater. Sci. 41, 3867 (2006).

[41] T. Wejrzanowski, R. Pielaszek, A. Opalinska, H. Matysiak, W. Łojkowski and K. J. Kurzydłwski, Appl. Surf. Sci. 253, 204 (2006). http://dx.doi.org/10. 1016/j.apsusc. 2006.05.089

[42] R. Pielaszek, "Analytical expression for diffraction line profile for polydispersive powders", in: Proceedings of the XIX Conference, Appl. Crystallography, Krakow, Poland, 43, 2003.
[43] M. N. Ashiq, M. J. Iqbal and I. H. Gul, J. Magn. Magn. Mat. 323, 259 (2011). http://dx.doi.org/10.1016/ j.jmmm . 2010.08.054

[44] G. Benito, M. P. Morales, J. Requena, V. Raposo, M. Vazquez and J. S. Moya, J. Magn. Magn. Mater. 234, 65 (2001). http://dx.doi.org/10.1016/ S0304-8853(01) 00288-8

[45] S. Che, J. Wang and Q. Chen, J. Phys. Cond. Mat. 15, L335 (2003). http://dx.doi.org/10.1088/ 0953-8984/15/22/101

[46] F. Yen-Pei, L. Cheng-Hsiung and P. Ko-Ying, Jpn. J. Appl. Phys. 42, 2681 (2003). http://dx.doi.org/10. 1143/JJAP . 42.2681

[47] C. Sürig, K. A. Hempel and C. Sauer, J. Magn. Magn. Mater. 268, 157 (1996).

[48] H. Sozeri, İ. Küçük and H. Özkan, J. Magn. Magn. Mater. 323, 1799 (2011).http://dx.doi.org/ 10.1016/j.jmmm. 2011.02.012

[49] J. Dho, E. K. Lee, J. Y. Park and N. H. Nur, J. Magn. Magn. Mater. 285, 164 (2005). http://dx.doi.org/ 10.1016/j.jmmm. 2004.07.033 